\title{
The Intersection of Potters and Environmental Sustainability - Pottery Glaze Cases
}

\author{
Ching-Lin Lu ${ }^{1}$, Tai-shen Huang ${ }^{1}$, Fang-Lin ${ }^{1}$ \\ ${ }^{1}$ Department of Industrial Design, Chaoyang University of Technology, Taichung, 436, Taiwan, R.O.C.
}

\begin{abstract}
Ceramics is a comprehensive expression of art and science. The ultimate goal of artistic creators is to create new presentations based on specific materials and superb techniques. Beside the bright and vivid presentation of ceramic art, we cannot ignore the process of glazing and ceramic firing, which is a process of high energy consumption and high carbon dioxide emission. We use life cycle assessment to calculate the environmental impact of the production phase. The impact at the manufacturing stage is different for different firing approach. The amount of $\mathrm{CO} 2$ emission in material and processing phase of design-2 is much more than that of Design- 1 . We need qualitatively and quantitatively explored to complement the lack of knowledge on the relationship between art creation materials and the impact on the environment.
\end{abstract}

\section{Introduction}

Scientific and technological progress has introduced different techniques (laser, sandblasting), materials (glazing, chemical agents, etc.) into the ceramics process, producing considerable results. Designers learn more and find techniques for their own skills, which build for specializing in the creation and providing motivation. However, in the brilliant pottery design, can the artist consider more?

The sustainability of the environment is a topic of concern to the public in recent years. Many international regulations on electronic products have widely established. For instance, RoHS stands for Restriction of Hazardous Substances. The Directive 2002/95/EC originated in the European Union and restricted the use of specific hazardous materials found in electrical and electronic products. The WEEE is the requirement for the final recycling of electronic products, and ECO design [1] is the procedural rationality specification for product design, considering the environmental impact of the entire lifecycle. Procedural and documentation requirements, a commitment to continual improvement, compliance with regulations, focused on the prevention of pollution integrated with product realization processes. The sustainability is usually through the 3R design method (Figure 1). First, it reduces unnecessary materials, additional functions, and simplifies the types of materials. Through the choice of materials, designer use materials and manufacturing procedures that have less impact on the environment. Besides, consider the environmental effects of product transportation, sales, and use phase. Reduce the consumption of energy, and increase the proportion of final recycling, which uses a disassembly design for re-use.

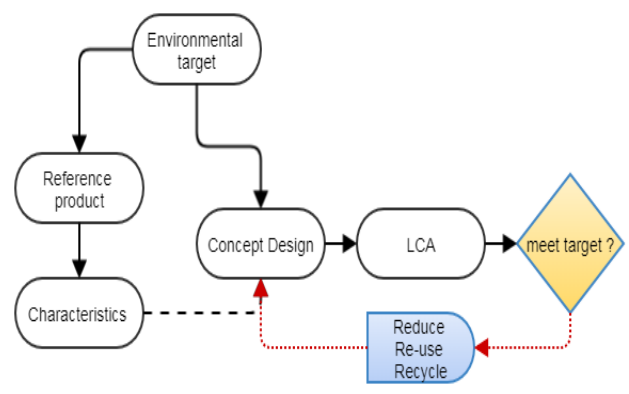

Fig. 1. Eco-design process

When the pottery artist meets with the sustainability, what kind of problems will he encounter? Although the pottery arts do not have the relevant laws and regulations, we try to explore the parts that related to the pottery arts from the sustainable development footprint of electronic products. The integration of aesthetics into sustainable issues will increase the acceptance by the general public.

\section{Pottery and Sustainability}

We begin with the materials, the choice of clay or glaze is related to the impact of the environment. Glazes and chemicals are also related to health issues. Secondly, we 
reviewed the manufacturing process. There are different dust generated during the production; a significant amount of energy required in over firing process. During the use phase, we concern about the cleaning and maintenance of the articles or the possible release of poisons. The final stage is the recycling phase. The prior documents were collected, classified and organized as follows.

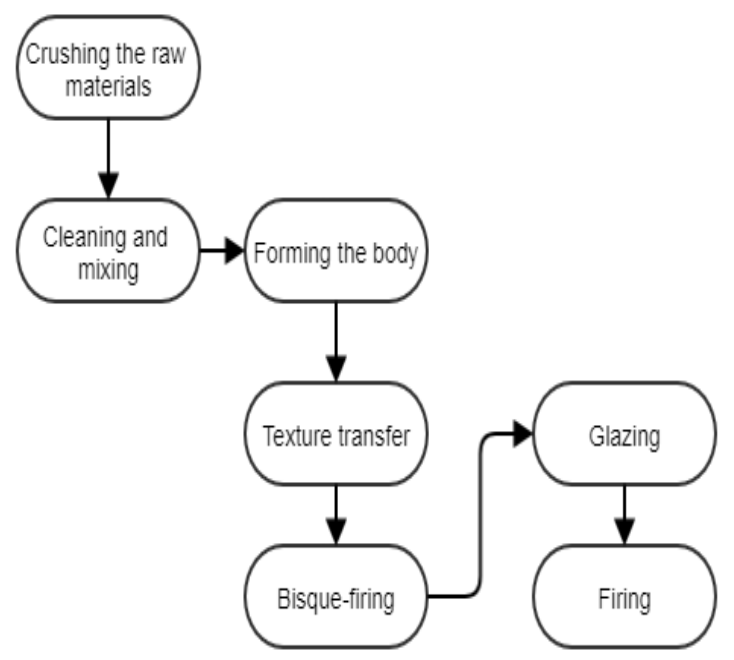

Fig. 2. Ceramic product's manufacturing flow, baked at high temperatures to achieve vitreous, translucence and low porosity [2].

The step includes crushing the raw materials, cleaning and mixing, forming the body, bisque-firing, glazing, and firing (Figure 2). The glaze slurry is screened and passed through magnetic filters to remove contaminants. An object is then applied to the ware utilizing painting, pouring, dipping or spraying. Different types of glazes produced by varying the proportions of the constituent ingredients. Firing is a further heating step. A periodic kiln consists of a single, refractory-lined, sealed chamber with burner ports and electric heating elements. A tunnel kiln maintains specific temperature zones continuously. This type of furnace is usually more energy efficient than a periodic oven.

During the firing process, carbon-based impurities burn out, chemical water evolves, and carbonates and sulfates begin to decompose (at 400 to 700 degrees Celsius). Gases generated must escape from the ware. Some of the minerals break down into other phases, and the fluxes present to react with the decomposing metals to form liquid glasses (at 700 to 1,100 degrees Celsius). During the ware is cooled and solidify, a strong bond formed between the grains.

In [3] investigated genotoxic effects of occupational exposure to lead acetate in pottery-glaze ceramic workers. The study was carried out on 30 exposed workers. "DNA diffusion and micronucleus test showed a higher influence of tested parameters to DNA damage." "Heavy metals (zinc, lead, cadmium, iron, chromium, copper, manganese, nickel and cobalt) were found to leach from the glazed surfaces of tea mugs [4]". The leachates used were: tea at $80^{\circ} \mathrm{C}$, orange juice at room temperature and $4 \%$ acetic acid at room temperature, $40^{\circ} \mathrm{C}$ and $60^{\circ} \mathrm{C}$, respectively. During the second stage of the firing process, where the ceramics were painted and glazed, the mean particle size ranged from 15 to $40 \mathrm{~nm}$ [5], and their number concentration peaked at $1.2 \times 106 \mathrm{~cm}^{-3}$. "Elemental analysis showed that the emitted nanoparticles contain significant amounts of lead." These findings provide new information for understanding the health impacts of traditional pottery manufacturing.

In [6] studied clayey materials come from the soil of Marrakech Haouz Plain. "The influence of grain size, mineralogical and chemical composition of these raw materials were evaluated." Inhibit lime blowing responsible for flaws to improve the quality of produced pottery. The most abundant oxides are $\mathrm{SiO}_{2}$ and $\mathrm{Al}_{2} \mathrm{O}_{3}$. " $\mathrm{MgO}$ is more abundant in $\mathrm{Ag}$ due to the presence of dolomite, whereas the $\mathrm{CaO}$ is more abundant in the sample due to calcite."

\section{Ceramic Coatings}

Ceramics is a comprehensive expression of art and science and technology, and its practicality and decorativeness are indispensable artifacts of life. Chinese ceramics influenced by the individuality of the producers and the environment in which they live. Each era and region has its unique performance and characteristics. It reflects the longing for truth, goodness, and beauty that people have demonstrated in their lives and cultures. The ultimate goal of artistic creators is to create new presentations based on specific materials and superb techniques. $\square$

Article [7] surveyed the several ways color introduced into ceramic coatings. The benefits and limitations of solution colors and the several classes of pigments, including opacifiers, were demonstrated in Figure 3 and [8].

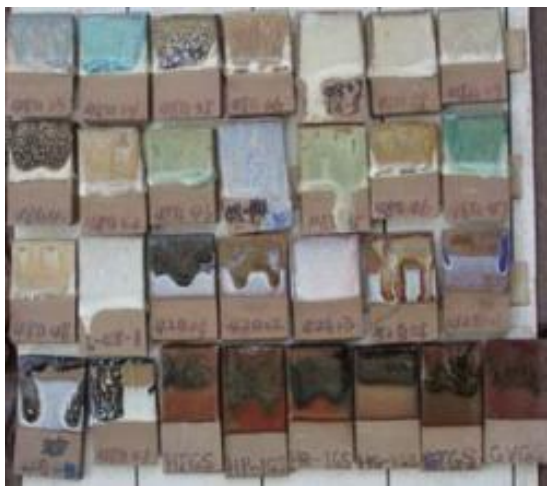

Fig. 3. Glaze testing

\subsection{Glaze}

There are different colors in the 6 cups which referring to different glaze formula. By interviewing with designers, the artist explained the differences in the presentation of these cups. 
This color is iron red, which accounts for $60 \%$ of iron in glazes. It will be clear if you carefully look upon the sample. Another one spotted which have a little bit of a flower. The heavenly eye ensemble and it will be outward in space. The Japanese monk brought back some dark monks from the Tang Dynasty. They can't tell what material it is. They only know that it is from Tianmu Mountain, so people call it Tianmu [9]. Unique of Jizhou kiln Tianmu glaze come from its unique craftsmanship, oil drops and more glaze differ in chemical composition and craftsmanship with the different type of hightemperature glaze (Figure 4).

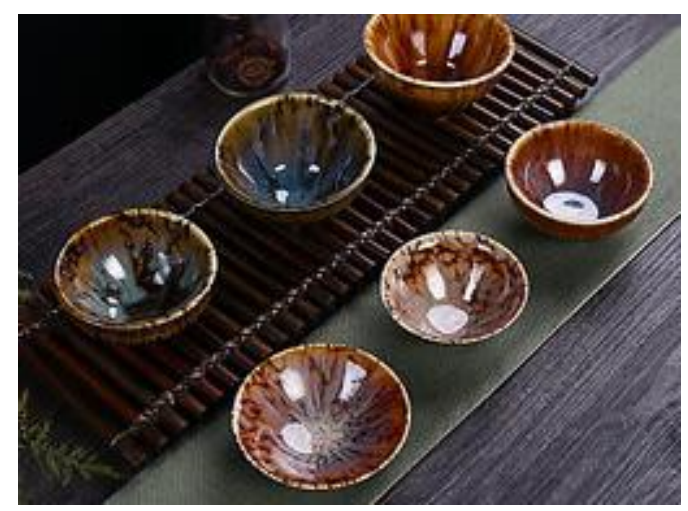

Fig. 4. Different glazed colors of the cups

The light reflected by the Tianmu, the main glaze is iron red. When the red is purple, then it will turn to black, and this black is all fired by the iron glaze. Copper glazes are green flowers with a different burning method. It appears red and purple. There are many spots above the cup. Color cannot be set in advance because there will be adding other materials to the oven. This official kiln and is historically used for the emperor. Those things are common fact; you see other names in the relevant period. On the cup, we mainly use the difference in its chemical composition, because the proportion of cobalt is relatively large, and it is not the same as a copper glaze with a unique expression.

\subsection{The creation of calligraphy art}

The development of ideas and the nature of original forms require the successful handling of technical details, each of which requires practical considerations and production techniques. With aesthetic beauty and the beauty of text lines as its appeal, it creates beautiful works of art [10]. As shown in Figure 5, the artists also make use of light and shadow changes and shapes, in the framework of the breakthrough space, the visual illusion, the work in the three-dimensional space due to ceramic forms and light changes which results in an optical illusion.

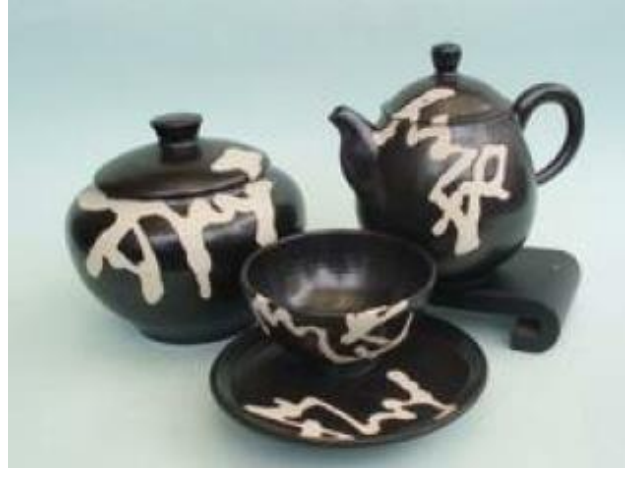

Fig. 5. Glazes article and calligraphy art [10]

\section{Encounter Point}

This article is based on the calligraphy art of glazes and discusses the encounter between the ceramic artist and the environment. We can imagine the working procedures of traditional ceramic designers from conception to production and presentation. Secondly, the development process based on the electronic product life cycle refers to the basic structure of the ECO design. Although they have different design thinking and procedures, we can connect the two sides to reduce the environmental impact and introduce the concept of sustainable design.

We choose two key areas to link the procedures. First, when selecting glaze materials, if you use recycled materials, you can reduce environmental impact. In the CRT recycling of the electronics industry [11], many rare minerals extracted and used in new glaze making. Second, in electronic products, they evaluated the impact of different manufacturing processes on environmental impacts. We will analyze the life cycle of two different design [10] ( materials and production procedures) for comparing the differences. Designers have the opportunity to choose a lower environmental impact from the process.

\section{Design of calligraphy texture}

The expression of calligraphy in traditional ceramic creation is nothing more than flat engraving and writing, intaglio carving, yang carving, and embossing technique. The adobe is hard and brittle, and the pointed needles can be used to describe the seal characters, starting and ending mellow, showing the real beauty of the texture. With a flat knife, the official script engraved, and the counter knife enters the billet. The horizontal width is straight and beautiful. The engraved strokes marked with mansard on both sides. More rigorously and neatly, with the blend of Chinese and Western aesthetics, modern calligraphy has been decoupled from the function of words and towards art. $\square$

The creation of modern ceramics is mostly embodied in form. Therefore, the performance of calligraphy is more diverse. Writing with a pen can better describe the meaning of galloping. Knife carving can produce the fun of stone and stone. During writing, the artist prefers ink 
black and blue color. The ceramic body absorbs water fast like a paper; blue and white with sharp fonts can produce through the fire melting glaze. Secondly, the choice of media, because of the different fonts and strokes, the forming techniques are entirely different, and the probability of failure is also high. It is essential to choose a material that is light and has a small shrinkage ratio. Another problem that followed was forming techniques and ways of expression to show a unified style. Since the plane writing has only a flat composition, there are considerable differences in the performance of the three-dimensional works. The expression of the surface pattern, the appearance of the sense of space, or the matching of the color with this work, or even the surface treatment such as engraving, must all be taken into consideration.

\subsection{Design-1}

The shaped of Design-1 (Figure 6) is a symmetrical halfround flower. The molded clay is mixed with clinker in Taiwan's Miaoli soil and formed on ceramic plates. Calligraphy arrangement utilizes proper layout of cursive lines. Texture performance presents the overall black matt glaze treatment. Glaze performance employed single black glaze, pen streaks to leave white fill.

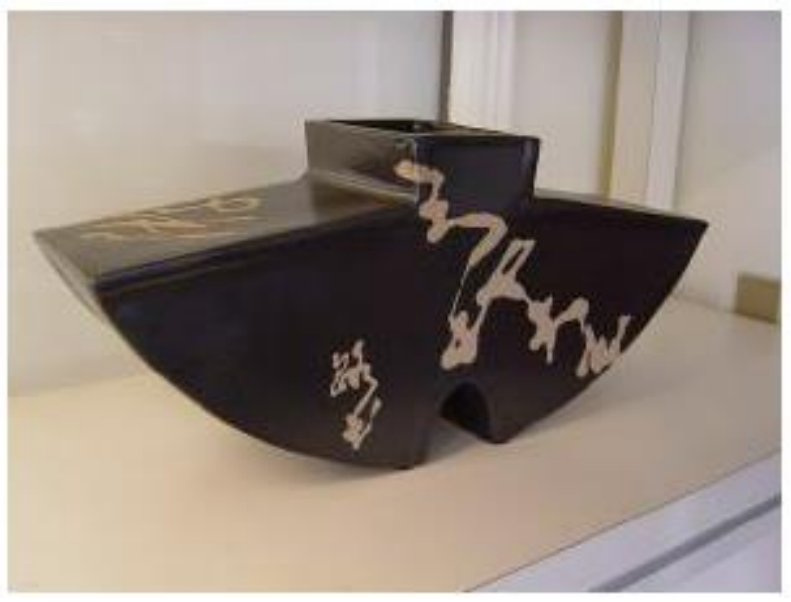

Fig. 6. The Design-1, symmetrical half-round

\subsection{Design-2}

The shaped of Design-2 (Figure 7) is a clay pot with specific three dimensional calligraphy texture.

- Appearance and shape: traditional flat shoulder, closed mouth, covered cans.

- Forming method: drawing building.

- Calligraphy arrangements: To express the central axis, the purpose of local yang carving and intaglio writing are used. The woody burnt ash glazes revealed the texture with a natural and unadorned peculiar gray.
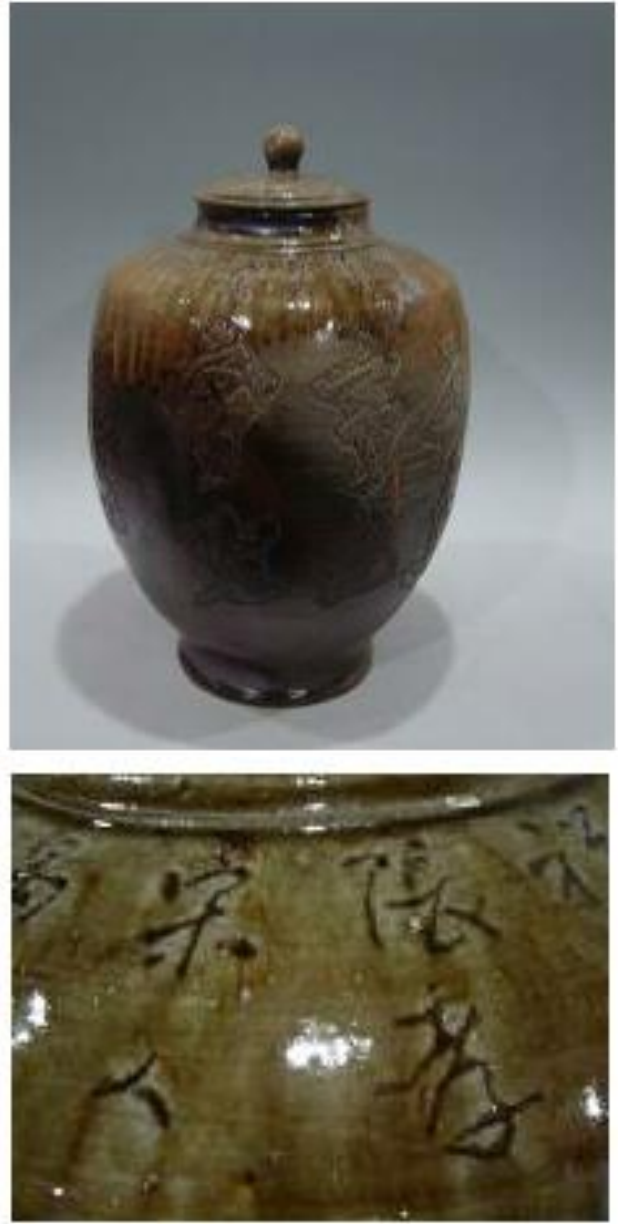

Fig. 7. Design-2, flat shoulder, closed mouth, covered pot

\subsection{LCA analysis of production phase}

Life cycle assessment software $[12,13]$ was selected to calculate the environmental impact of the production phase. In [13], the analysis has been carried out after the construction of the building with ISO 14040 [14]. However, in cases of LCA used with a constructive process, useful aspects for the definition of the results related to these uncertainties should be introduced. We can find two different kinds of design of artistic representations. The firing step of Design-1 uses the 9000-watt electric furnace for 12 hours. The firing step of Design-2 uses $2.5 \mathrm{~m}^{3}$ firewood burned within a closed oven for more than two weeks. A total number of sharing pot divides the amount $\mathrm{CO}_{2}$. The emission results are shown in Figure 8. The impact at the manufacturing stage is different; an amount of $\mathrm{CO}_{2}$ emission in material and processing phase of Design-2 is much more significant than that of Design-1. 


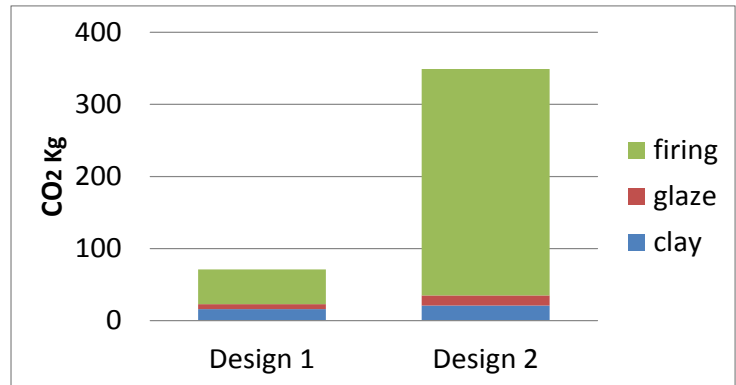

Fig. 8. Life cycle assessment of Design $1 \& 2$ : the amount of $\mathrm{CO} 2$ emission in material and processing phase

\section{Conclusions}

Science and technology introduce different tools and material techniques into the ceramic surface treatment and produce significant results. The designer finds skills and provides power for creation. Although the pottery arts do not have the relevant eco-design regulations, pottery arts can transfer experience from sustainable development footprint of the electronic industry. In the vivid presentation of ceramic art, we cannot ignore the process of glazing and ceramic firing, which is a process of high energy consumption and high carbon dioxide emission. The eco-design process in the electronics industry is worth learning for ceramic designers. For example, from different materials, different soil quality, different glazing methods, and ceramic firing processes; what kinds of combination can reduce the environmental impact?

In the future, we need qualitatively and quantitatively explored to complement the designers' lacking scientific knowledge. In addition to the perceptual presentation, it is also possible to understand the relationship between materials and the impact on the environment. Through the adjustment of the design process, guiding the sustainable issues into the design will help the ceramic art designers walk onto a sustainable path which increases the ecoawareness of the general public.

\section{Acknowledgment}

The author thanks Professor Tai-Sheng Huang and Dr. Fang-Lin Chao for useful suggestions.

\section{References}

1. Donnelly, K., Beckett-Furnell, Z., Traeger, S., Okrasinski, T. and Holman, S., 2006. Eco-design implemented through a product-based environmental management system. Journal of Cleaner Production, 14(15-16), pp.1357-1367.

2. http://www.madehow.com/Volume1/Porcelain.ht $\mathrm{ml}$

3. Kašuba, V., Rozgaj, R., Milić, M., Želježić, D., Kopjar, N., Pizent, A., ... \& Jazbec, A. 2012 Evaluation of genotoxic effects of lead in potteryglaze workers using micronucleus assay, alkaline comet assay and DNA diffusion assay. International archives of occupational and environmental health, 85(7), pp. 807-818..

4. Ajmal, M., Khan, A., Nomani, A.A. and Ahmed, S., 1997. Heavy metals: leaching from glazed surfaces of tea mugs. Science of the total environment, 207(1), pp.49-54.

5. Voliotis, A., Bezantakos, S., Giamarelou, M., Valenti, M., Kumar, P. and Biskos, G., 2014. Nanoparticle emissions from traditional pottery manufacturing. Environmental Science: Processes \& Impacts, 16(6), pp.1489-1494.

6. El Boudour El Idrissi, H., Daoudi, L., El Ouahabi, M. and Fagel, N., 2016. Flaws linked to lime in pottery of Marrakech (Morocco). Journal of Materials and Environmental Science.

7. Zamek, J., 1999. What Every Potter Should Know: Answers and Solutions to Common Pottery Problems. Krause Publications.

8. Eppler, R.A., 2003. Putting color into glazes and enamels. Transactions of the Indian Ceramic Society, 62(4), pp.181-191.

9. Guodian, C., 2011. See Traditional Ceramic Technology from Ceramic Materials of Jizhou kiln Porcelain, Jiangsu Ceramics, 3, p.005.

10. C.L Lu, The Spatial Manifestation of Calligraphy in Ceramic Art-Lu Qinglin's Creation of Pottery Creation, master thesis, 2008, Taiwan Art University.

11. Andreola, F., Barbieri, L., Corradi, A., Ferrari, A.M., Lancellotti, I., and Neri, P., 2007. Recycling of EOL CRT glass into ceramic glaze formulations and its environmental impact by LCA approach. The International Journal of Life Cycle Assessment, 12(6), pp.448-454.

12. Cargnin, M., Salgado, A.L.F., Gomes, J.M., Junior, A.D.N., and Hotza, D., Case study of the comparative life cycle analysis (LCA) of glazed porcelain tile and red-body stoneware tile production.

13. Lolli, V., Panone, V. and Benedetti, A., 2015. Comparative analysis, through LCA Method, between a house with laminated wood structure and straw infill and a house with reinforced concrete structure and brick infill.

14. Guinée, J.B., 2002. Handbook on life cycle assessment operational guide to the ISO standards. The international journal of life cycle assessment, 7(5), p.311. 